\title{
Aplicação da metodologia AV/EV ao design: um estudo de caso da empresa de calçados Isabela Sales
}

\author{
Application of AV / EV methodology to design: a case study of shoes company Isabela \\ Sales
}

COHEN, Lauro Arthur Farias Paiva; Graduando em design; Universidade do Estado do Pará - UEPA laurocohenn@gmail.com

OLIVEIRA, Joseana da Silva; Graduanda em design; Universidade do Estado do Pará - UEPA joseana.oliveira@outlook.com

GEMAQUE, Amanda Madalena da Silva; Doutoranda em Ciências Ambientais; Docente Universidade do Estado do Pará - UEPA amanda.gemaque@yahoo.com.br

\section{Resumo}

Esta pesquisa teve como objetivo investigar as etapas do processo produtivo da empresa autoral do ramo de calçados "Isabela Sales Designer", visando contribuir com seu funcionamento eficaz por meio da aplicação da Metodologia Análise de Valor - AV/EV. A pesquisa foi exploratória e descritiva, com abordagem qualitativa. Foram realizadas entrevistas durante visitas ao atelier da empresa entre agosto e dezembro de 2017. Em seguida, aplicou-se o Plano de Trabalho de AV/EV proposto por Pereira Filho (1994), seguido da formulação de uma matriz SWOT. Os resultados indicaram a sustentabilidade e a inovação como forças do negócio, com a utilização da câmara de ar de pneus como matéria-prima de baixo custo e design diferenciado nos principais produtos. Contudo, como fraqueza, destacou-se a baixa capacidade produtiva. É recomendável o investimento em novas parcerias visando o aumento da produção, além de ações de marketing mais próximas ao públicoalvo e em espaços que compartilhem de seu conceito.

Palavras-chave: Design, valor, sustentabilidade e inovação.

\begin{abstract}
The objective of this research was to investigate the steps of the productive process of the Isabela Sales Designer footwear company, in order to contribute to its effective functioning through the application of the Value Analysis Methodology - AV / EV. The research was exploratory and descriptive, with a qualitative approach. Interviews were conducted during visits to the company's atelier between August and December 2017. Then, the AV / EV Work Plan proposed by Pereira Filho (1994) was applied, followed by the formulation of a SWOT matrix. The results indicate sustainability and innovation as business forces, with the use of the tire tube as a low cost raw material and differentiated design in the main products. However, as weakness, the low production capacity stands out. It is suggested to invest in new partnerships to increase production, marketing actions closer to the target audience and in spaces that share their concept.
\end{abstract}

Key-Words: Design, value, sustainability and innovation. 


\section{Introdução}

Um dos principais objetivos de uma empresa é conseguir agregar valor aos seus produtos, de maneira que possibilite que alcance estabilidade no mercado, com o intuito de manter seu público fiel e obter retorno financeiro satisfatório. Segundo Carmona et.al. (2016) a vantagem competitiva de uma empresa está relacionada diretamente ao potencial de criação de valor em suas ações no mercado e ao não envolvimento de seus concorrentes em projetos similares.

Neste sentido, a inovação é um elemento fundamental na criação de valor das empresas e representa para elas uma fonte de vantagem competitiva, mesmo com a instabilidade do mercado (OLIVEIRA; BASSO, 2014). Segundo o Manual de Oslo, a inovação seria a implementação de um produto novo, um processo, um novo método de marketing ou um novo método na organização dos negócios (OECD, 1997). Desse modo, as empresas necessitam inovar para que possam diminuir as incertezas, e assim, desenvolver seus negócios.

A busca por renovação no interior das organizações foi acelerada com crescimento dos debates acerca da necessidade de um modo de vida mais sustentável. Essa pressão é mais perceptível em indústrias com maiores potenciais de impactos ambientais e visibilidade em sua atuação (SEURING; MULLER, 2008). Entretanto, essa questão é algo muito forte também em pequenas empresas ou em negócios locais, como é o caso do objeto de estudo dessa pesquisa, a empresa "Isabela Sales Designer", que trabalha no ramo de calçados confeccionados de forma artesanal e com materiais alternativos, como a câmara de ar de pneus e peças de jeans que seriam descartadas pelos consumidores.

Segundo Kluyver (2010) entre os maiores desafios para as empresas nos próximos 30 anos estão à degradação ambiental, a busca por práticas mais sustentáveis e o tratamento de resíduos. Para Bistagnino (2009) a sustentabilidade é uma questão desafiadora para artesãos por exigir conhecimento sobre aspectos socioeconômicos, mudanças de comportamentos e adequação ao novo modelo de produção.

Nesse contexto, o design pode contribuir com a transformação e inovação, por apresentar alternativas que tornam o mercado mais responsável e competitivo (FLETCHER; GROSE, 2011). Este novo design, que incorpora sustentabilidade e a inovação social, precisa de novas abordagens e metodologias que fundamentem e direcionem o cenário complexo que vem se formando (MORAES, 2010).

Além disso, metodologias como a Análise de Valor - AV podem colaborar para essa renovação por se relacionar ao esforço de pesquisa por novos materiais, com menor custo (DOMINGUES et al., 2013). Incorporada a ela, a Engenharia de Valor - EV auxilia o desenvolvimento de novos produtos, aperfeiçoando seus processos de produção e aprimorando seus componentes, com o objetivo de minimizar seus custos, mas não reduzir a qualidade (WIENHAGE et al., 2012).

Dentro de uma perspectiva sustentável e interdisciplinar, se torna relevante investigar as contribuições que a metodologia AV/EV pode oferecer ao design, na busca por inovações que sejam capazes de agregar valor aos produtos e possam atender as novas exigências do mercado. Assim, 0 objetivo dessa pesquisa foi investigar as etapas do processo produtivo da empresa autoral do ramo de calçados "Isabela Sales Designer", visando contribuir com seu funcionamento eficaz por meio da aplicação da metodologia de análise de valor. 


\section{Fatores que agregam valor ao produto}

Uma gestão inclinada à criação de valor pode servir como ferramenta eficaz na tomada de decisões. Dessa forma, é possível analisar a atuação da empresa e verificar as estratégias mais adequadas à sua realidade (GUINDANE et al., 2011). Assim, a seleção de métodos que potencializem a produtividade da organização e o maior investimento em elementos como o marketing, podem contribuir para agregar valor aos produtos e, consequentemente, aumentar seus rendimentos de forma exponencial. A seguir, serão apresentadas algumas características desses fatores.

\subsection{Marketing e design}

Atualmente é comum muitas pessoas associarem ações de marketing com a boa gestão de empresas e pessoas. Segundo Las Casas (2009), as empresas que visam o lucro aplicam técnicas de marketing no processo de venda, assim, de acordo com o autor, a forma como o produto se projeta e a forma como a comunicação (promoção seja através de anúncios, exposições ou através de redes sociais) é feita é recompensada por meio do retorno de uma boa administração (preço e valor cobrado).

Nesse contexto, é preciso convencer o cliente das conviç̧ões positivas da empresa, com bons valores e ideais, pois cada vez mais os consumidores estão buscando ou precisando ver soluções para um mundo melhor. Ao invés de tratar a pessoa como um simples consumidor, os profissionais de marketing têm que pensar neles como indivíduos plenos, com mente, coração e espírito (GOMES; KURY, 2013).

Seguindo essa linha de pensamento, o "Marketing 3.0" visa satisfazer esse consumidor e todos seus anseios. Anseios esses gerados por uma série de avanços tecnológicos, de mercado e de comunicação ao longo dos anos. Ele tem a ver com marketing emocional, com marketing do espírito humano (GOMES; KURY, 2013). "As empresas que o praticam querem mudar o mundo. Não conseguirão fazê-lo sozinhas. O Marketing 3.0 representa a colaboração de entidades de negócios que compartilham conjuntos semelhantes de valores e desejos (KOTLER, 2010, p.12)."

No interior de uma organização, o designer não somente projeta seguindo uma metodologia, mas se relaciona com diferentes áreas e setores para realizar sua função. Dessa forma, por meio de branding e desenvolvimento de marcas, pode proporcionar a ampliação das estratégias de marketing trabalhadas. Nesse sentido, as ações de marketing permitem a empresa atingir objetivos quantitativos (obter lucro / fatia de mercado) e qualitativos (visibilidade, projetar imagem positiva no mercado).

\subsection{Sustentabilidade e Design}

A repercussão sucessiva da sustentabilidade integrada a produtos, processos e comportamentos é uma questão recorrente tendo em vista a preocupação com problemas relacionados a degradação ambiental (CASAGRANDE JR, 2004). Considerando-se tais adversidades, de acordo com Manzini e Vezzoli (2002), percebe-se a exigência social em apropriar-se de princípios mais sustentáveis, assim, cabe ao sistema produtivo adotar em seus processos as prerrogativas de desenvolvimento sustentável.

Logo, torna-se necessário adequar o meio a realidade que emerge por um modo de vida mais ecológico com respeito aos limites de recursos e energia presentes na natureza. Nesse sentido, aplica-se a sustentabilidade e a mesma consiste na estratégia sistêmica produtiva que considera o 
equilíbrio entre os parâmetros socioculturais, econômicos e ambientais, e, possui finalidade de gerar bem-estar e qualidade de vida a sociedade (OKADA; BERLIM, 2014).

Os valores sustentáveis têm objetivo de propor mudanças na configuração técnica atual do sistema, ou seja, propõe o abandono de métodos cartesianos e coloca em prática soluções que prezam a diversidade cultural com a potencialização das características regionais, tornando assim, os processos mais eficientes com resultados de produtos e serviços mais eficazes (CASAGRANDE JR, 2004). Os princípios de sustentabilidade apresentam viés educativo e conscientizador, ou seja, possui significativa relevância social, portanto, hábitos, costumes e consumo da sociedade são repensados, e apesar das adversidades, busca-se adequar o modo de vida do indivíduo em perspectiva mais sustentável (DA SILVA; HEEMANN, 2007).

Com base no desenvolvimento sustentável e no panorama sistema-produto, considera-se a concepção de produtos e serviços na área do design, conforme Manzini e Vezzoli (2002) e a partir disso tem se explorado e valorizado com frequência os processos de slow fashion e upcycling. 0 slow fashion visa à produtividade em consonância com os critérios de sustentabilidade, ou seja, dispõe-se a produzir com mais responsabilidade ecológica e com finalidade de gerar mudanças de consumo. Além de presta-se a preservação dos recursos naturais, objetiva o processo eficiente para o alcance de resultados criativos e inovadores (ANICET; BESSA; BROEGA, 2011). De acordo com o autor, o upcycling configura-se na reutilização de material com baixo ou isento uso de energia, sendo este processo e materiais valorizados em mercado por seguir princípios ecológicos.

Em todo o contexto exposto, deve-se levar em consideração o papel do designer. De acordo com Peltier (2009), o profissional tem como obrigação propor uma proposta criativa em um contexto mais respeitoso ao meio ambiente. Nesse sentido, segundo o autor, o design sustentável permite responder às necessidades socioeconômicas e ambientais dos consumidores, propondo formas inovações, materiais alternativos e procedimentos que gerem impacto ambiental mínimo em cada etapa do ciclo de vida do produto.

\section{Metodologia}

A pesquisa teve um caráter exploratório e descritivo, baseada em um estudo de caso, com abordagem qualitativa. Essa abordagem permite que o pesquisador entre em contato direto com o ambiente e a situação que está sendo investigada, favorecendo um contato próximo com o informante e permitindo uma visão mais abrangente do fenômeno (MARCONI; LAKATOS, 2011).

Para melhor compreensão da empresa autoral de calçados investigada, foram realizadas visitas técnicas ao atelier da designer entre agosto e dezembro de 2017, no sentido de obter informações sobre questões mercadológicas e processos produtivos. As entrevistas foram realizadas por meio de conversa oral, fato que permite a compreensão dos contextos sociais específicos, conforme o método prescrito pelos autores.

Os pesquisadores procederam entrevistas com formulários semiestruturados, formado por perguntas embasadas na Fase de preparação da metodologia de Plano de Trabalho de AV/EV. Segundo Pereira Filho (1994), tal método incentiva geração de alternativas dos processos com a finalidade de propor mudanças. Logo, o objetivo da metodologia é avaliar e estudar determinada instituição com base nas premissas de Análise de Valor. O Plano de Trabalho AV/EV (figura 1) propõe etapas (um total de 6 fases), finalidades a serem alcançadas e passos necessários para obter resultados. 


\section{Artigo Completo}

Figura 1 - Plano de trabalho: Análise de Valor

\begin{tabular}{|c|c|c|c|c|c|c|}
\hline \multirow[b]{2}{*}{ ETAPAS } & \multirow[b]{2}{*}{$\begin{array}{l}\text { 1.Fase de } \\
\text { Preparaçāo }\end{array}$} & \multirow[b]{2}{*}{$\begin{array}{l}\text { 2.Fase de } \\
\text { Informação }\end{array}$} & \multirow[b]{2}{*}{$\begin{array}{l}\text { 3.Fase de } \\
\text { Análise }\end{array}$} & \multirow[b]{2}{*}{$\begin{array}{l}\text { 4.Fase de } \\
\text { Criatividade }\end{array}$} & \multirow{2}{*}{$\begin{array}{l}\text { 5.Fase de } \\
\text { Desenvolvimento }\end{array}$} & PEREIRA FILHO, 1994 \\
\hline & & & & & & $\begin{array}{l}\text { 6.Fase de } \\
\text { Implantaçäo }\end{array}$ \\
\hline FINALIDADES & $\begin{array}{l}\text { Medidas } \\
\text { preparatórias }\end{array}$ & $\begin{array}{l}\text { Conhecer a } \\
\text { situaçăo atual }\end{array}$ & $\begin{array}{l}\text { Examinar a } \\
\text { situaçăo atual }\end{array}$ & Obter ideias & $\begin{array}{l}\text { Formular } \\
\text { proposiçס̃es }\end{array}$ & $\begin{array}{l}\text { Apresentar e } \\
\text { implantar a } \\
\text { soluçăo proposta }\end{array}$ \\
\hline PASSOS & $\begin{array}{l}\text { 1.1.Escolher o } \\
\text { objeto } \\
\text { 1.2.Delimitar o } \\
\text { objetivo } \\
\text { 1.3.Compor o } \\
\text { grupo de } \\
\text { trabalho } \\
\text { 1.4.Planejar as } \\
\text { atividades }\end{array}$ & $\begin{array}{l}\text { 2.1.Obter } \\
\text { informaçøes } \\
2.2 \text { Obter os } \\
\text { custo } \\
\text { 2.3.Descrever } \\
\text { as funçöes }\end{array}$ & $\begin{array}{l}\text { 3.1.Análisar as } \\
\text { funçర్es } \\
\text { 3.2. Determinar } \\
\text { as funçס̋es } \\
\text { criticas } \\
\text { 3.3.Enunciar } \\
\text { problemas }\end{array}$ & $\begin{array}{l}\text { 4.1.Obter } \\
\text { ideias } \\
\text { 4.2.Agrupar } \\
\text { ideias }\end{array}$ & $\begin{array}{l}\text { 5.1.Formulare } \\
\text { desenvolver } \\
\text { alternativas } \\
5.2 \text {.Viabilizar } \\
\text { tecnicamente } \\
\text { 5.3. Viabilizar } \\
\text { economicamente } \\
\text { 5.4.Decidir }\end{array}$ & 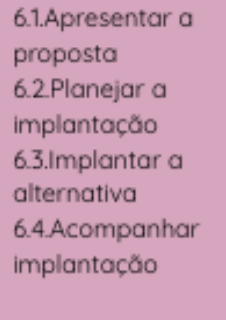 \\
\hline
\end{tabular}

Fonte: Adaptado de Pereira Filho (1994)

Segundo Csillag (1995) a metodologia AV/EV é o esforço organizado, com o foco na análise das funções de bens e serviços para atingir as características essenciais de maneira mais rentável. Portanto, foi organizado o plano de trabalho na empresa estudada com base em Pereira Filho (1994). Além da utilização da metodologia do Plano de Trabalho, foi necessário a aplicação da ferramenta Análise SWOT. Criada por Kenneth Andrews e Roland Cristensen, professores da Harvard Business School, ela estuda a competitividade de uma organização segundo quatro vertentes: Strengths (Forças), Weaknesses (Fraquezas), Oportunities (Oportunidades) e Threats (Ameaças) (OLIVEIRA, 2007).

Segundo Daychouw (2007) a análise SWOT é uma ferramenta útil para análises de ambientes, fundamental a gestão e o planejamento estratégico de uma empresa. Ferrell e Hartline (2009) ressaltam que o gestor deve analisar as potencialidades e as deficiências das organizações. Suas forças e fraquezas podem existir por recursos possuídos ou não pela empresa ou da natureza do relacionamento entre a empresa e seus consumidores, empregados ou organizações exteriores. As oportunidades e ameaças existem fora da empresa, independente de forças e fraquezas, ocorrem tipicamente dentro dos ambientes competitivos.

\section{Resultados e discussão}

\subsection{A empresa Isabela Sales}

A empresa atua no mercado autoral na criação de calçados com viés conceitual mais sustentável, a partir da reciclagem de materiais descartados, como câmara de pneus e peças de jeans, conforme a figura 2. 


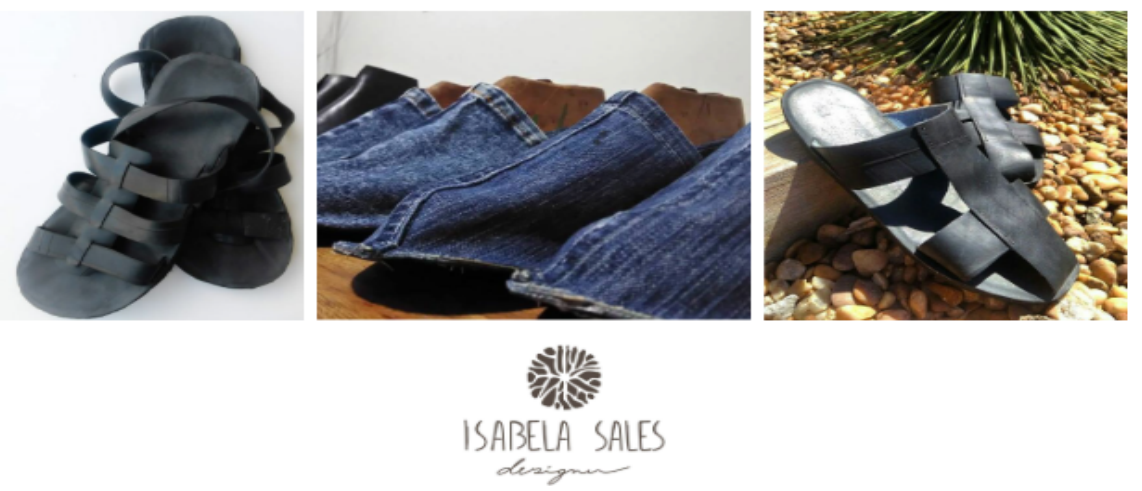

Fonte: Instagram, 2017

No que tange ao aspecto produtivo, a empreendedora possui atelier próprio, situado em sua residência. Portanto, foram eliminados custos como o aluguel, o que pode ser considerado um ponto positivo, haja vista que a empresa ainda é recente no mercado e não possui capital suficiente para investir um ponto comercial. Ademais, a localização atual de trabalho é estratégica por estar próximo ao centro da cidade de Belém, o que facilita a aquisição de insumos e a logística de entregas dos produtos. Os calçados, conforme figura 3, são confeccionados artesanalmente, com auxílio apenas de uma máquina de costura.

Entretanto, está nos planos da empresa adquirir uma lixadeira e uma máquina de cortar solado, com o objetivo de aperfeiçoar seus processos, e assim obter os produtos de maneira mais rápida. De acordo com a empreendedora, a implementação desse maquinário não irá reconfigurar o processo artesanal vinculado aos seus produtos. Ela considera o caráter artesanal relacionado às suas sandálias como aspecto fundamental de conceito e valor, tendo em vista que o usuário consome seu produto não apenas pelo resultado, mas sim por todo processo produtivo que agrega tanto o design, quanto o artesanato.

Figura 3 - Designer Isabela Sales, seus produtos e ferramentas de trabalho

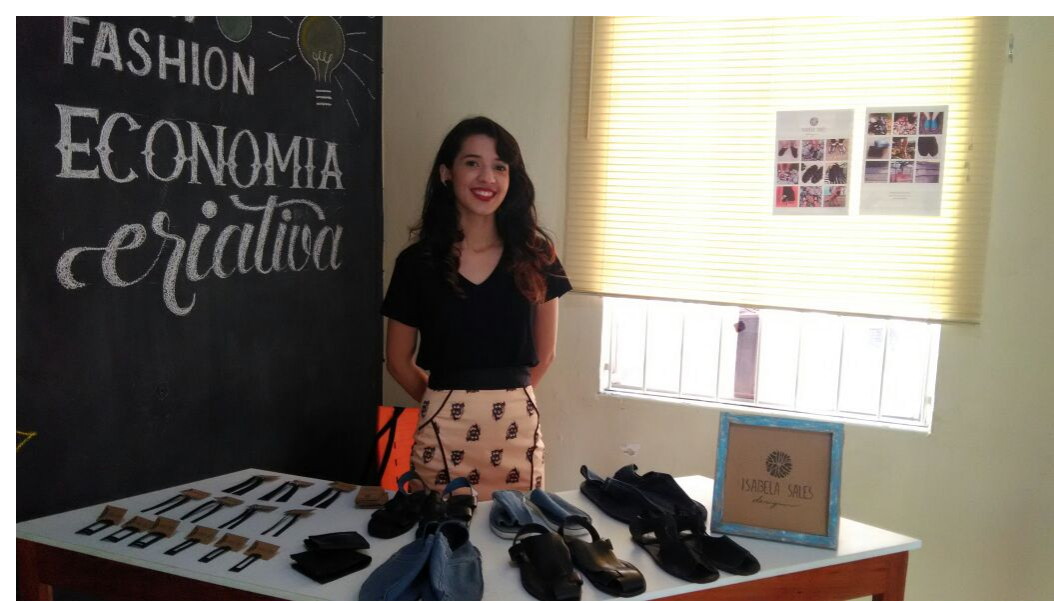

Fonte: Autores, 2017 
Segundo Fragata e Silva (2016) a sustentabilidade e a inovação são manifestadas no artesanato por meio das funcionalidades e representatividade na sua cadeia produtiva. Sua evolução pode ser percebida pela inserção de materiais com insumos sustentáveis ou recicláveis, e também, pela junção de técnicas tradicionais e modernas na produção dos produtos. O foco da empresa é atingir usuários que tenham uma consciência sustentável, senso crítico em relação à causa e ao adquirir o produto tenha consciência dos impactos que serão evitados. Além disso, o público-alvo são jovens universitários com idade de 19 a 28 anos, conforme ilustrado na figura 4.

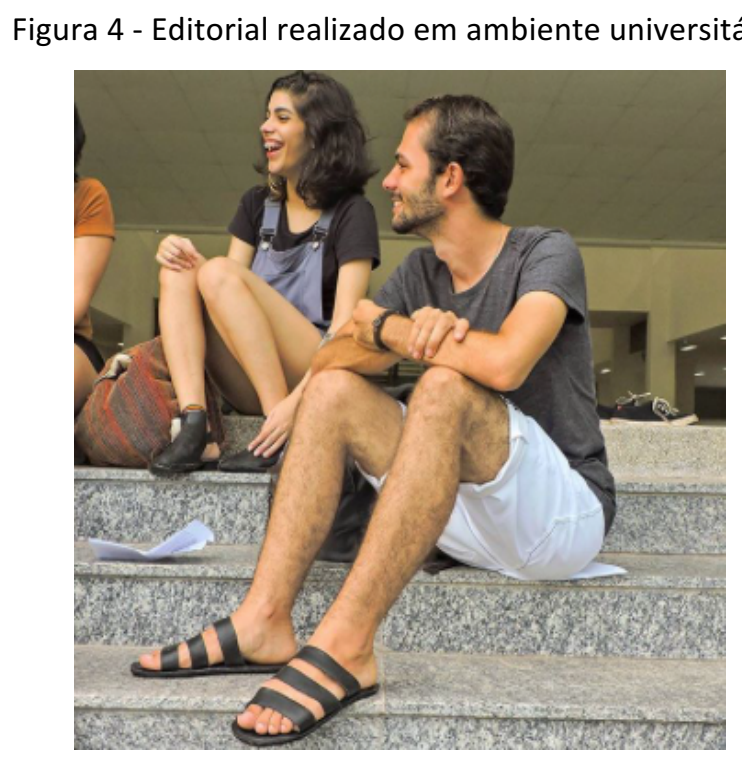

Fonte: Instagram, 2017

\subsection{Aplicação da Matriz SWOT}

Conhecido como Modelo de Harvard a análise SWOT (Strengths, Weaknesses, Opportunities e Threats), também chamada de análise FOFA, por conta de sua tradução para o português, surge na década de 60 e consiste na ferramenta responsável por explorar as peculiaridades do cenário, de maneira estratégica, com a finalidade de se obter respostas sobre o desempenho atual de qualquer organização (CHIAVENATO, SAPIRO, 2003). De acordo com o autor, o objetivo da ferramenta é confrontar as oportunidades e as ameaças presentes no ambiente externo, considerado o meio não controlado por indivíduos da organização. Além disso, avalia os pontos fortes e fracos existentes no ambiente interno, sendo este controlado por agentes da empresa.

A matriz SWOT é aplicada à empresa, apresenta como forças o domínio na produção dos calçados, o modo de produção artesanal que agrega valor ao produto e a isenção de custos do aluguel do espaço de trabalho. Já entre as fraquezas do empreendimento pode-se destacar que a proprietária possui apenas uma estagiária, sendo que, por esta razão a empreendedora torna-se sobrecarregada em funções, o que acarreta na centralização do trabalho. Abaixo, a figura representa as forças e fraquezas da empresa de calçados Isabela Sales. 


\section{Artigo Completo}

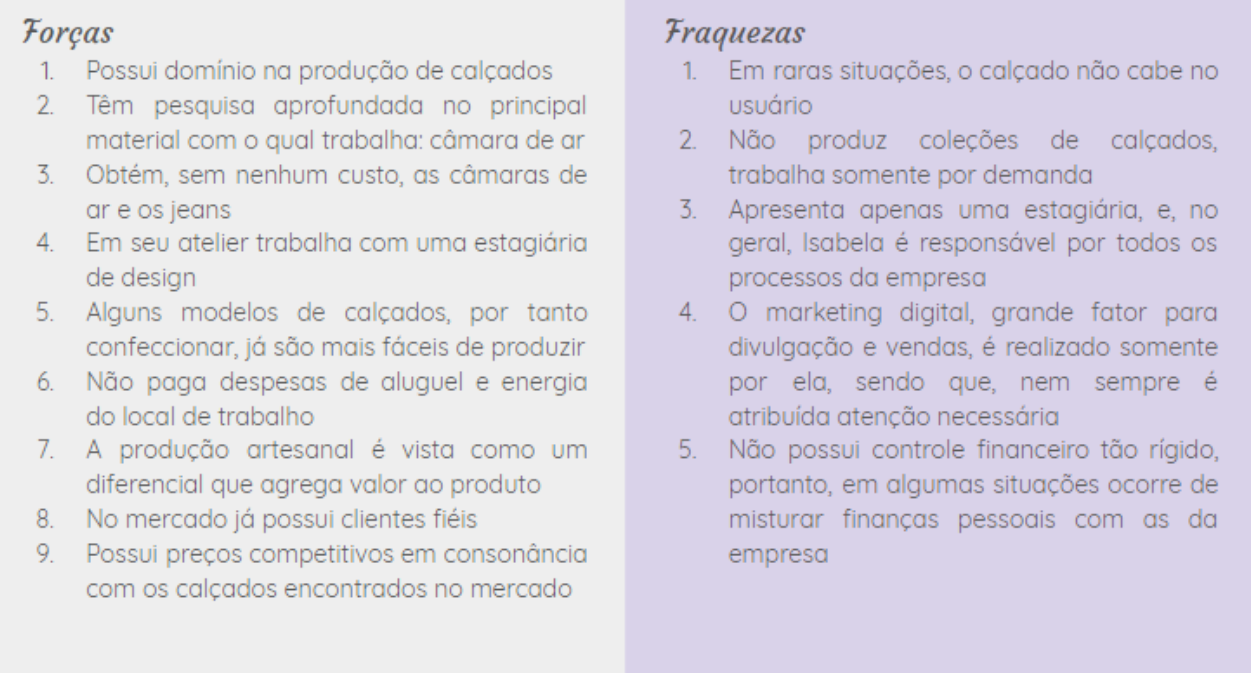

Fonte: Autores, (2017)

No que diz respeito ao ambiente externo, que categoriza as oportunidades e as ameaças, destaca-se como pontos oportunos: sustentabilidade agregado ao conceito do produto e inovação em material utilizado em calçados. Quanto às ameaças concentra-se na produção somente por demanda; instabilidade financeira; e a impossibilidade de pagar salário a funcionário, conforme figura 6.

Figura 6 - Oportunidades e ameaças da matriz SWOT aplicada à realidade da empresa

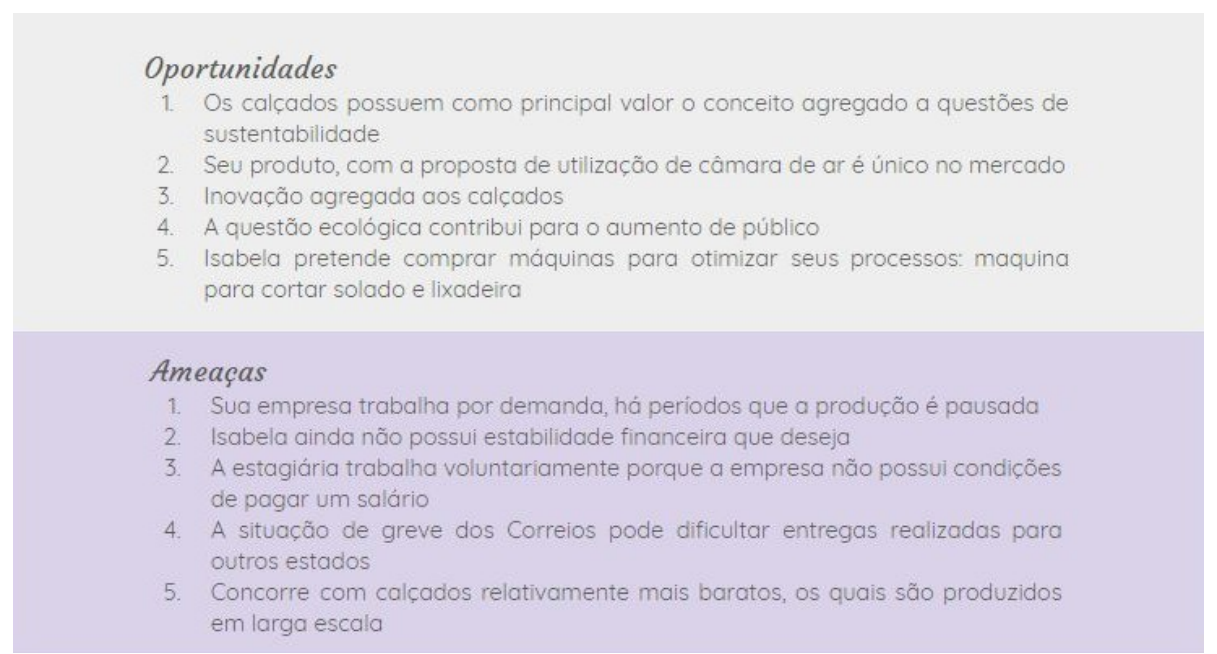

Fonte: Autores, 2017

Ao realizar a análise da matriz SWOT é possível manter uma relação proveitosa entre oportunidades e forças nos seguintes quesitos: matéria-prima, principalmente no que diz respeito a utilização de câmara de ar; a sustentabilidade empregada no modo produtivo associado ao material utilizado; e inovação, por empregar a câmara de ar na confecção de calçados. 0 cruzamento entre oportunidades e pontos fortes configura a situação de alavanca, ou seja, são os aspectos positivos da organização que devem ser mantidas em pleno desenvolvimento, conforme Daychoum (2007). 
Segundo o autor, ao estabelecer a associação entre ameaças e fraquezas é possível visualizar com clareza os problemas inerentes a empresa. Destacam-se como os principais gargalos a questão de produção somente por demanda, com inexistência de coleção que acompanha tendências. Ademais, a concorrência pode ser desleal, quando os meios de comunicação não agem de maneira tão frequente, ou seja, a não priorização do marketing, tal situação é classificada como uma fraqueza, entretanto pode torna-se uma ameaça diante os concorrentes diretos.

Ao confrontar as ameaças com as forças obtêm-se a defesa, pois, a partir do ponto forte presente dentro da empresa será possível evitar as adversidades das ameaças. Neste sentido, mesmo a empreendedora enfrentando a concorrência com calçados mais baratos e fabricados em massa, a proprietária mantém a sua qualidade com base no domínio na produção artesanal e na agregação de conceito ecológico, além de estabelecer o contato mais próximo com os usuários.

Ao relacionar oportunidades e fraquezas é possível visualizar as restrições que consiste em oportunidades dificultadas por pontos fracos da instituição. Com base nisso, o conceito de produto ecologicamente sustentável agrega valor no mercado, entretanto, o baixo investimento em meios de comunicação, como o marketing digital, dificulta a divulgação dos calçados ao público, tornando assim, uma restrição de mercado.

\subsection{Aplicação da metodologia AV/EV}

\subsubsection{Fase de preparação}

Na primeira etapa da metodologia, são utilizadas algumas medidas de preparação, em uma forma generalizada, para que se possa conhecer sobre o contexto que a empresa se encontra, quais as suas projeções e como a análise de valor pode auxiliar na potencialização da sua realidade e da forma em que a marca é vista pelos consumidores. Essa aplicação é feita, pois de acordo com Pereira Filho (1994), não é viável estudar cada item, produto, processo e material em razão da quantidade de recursos gastos, seja tempo, dinheiro ou mão de obra.

Nesse sentido, conforme o autor, a metodologia AV/EV utiliza os recursos disponíveis para obter o máximo de retorno possível, além de que a escolha dos critérios de informação garantirá que os esforços a serem despendidos com esse método se concentrem nos projetos e ações com maior benefício monetário. Foi elaborada uma pequena entrevista que seria aplicada com a dona da empresa, e com as respostas eram esperadas algumas informações sobre os produtos comercializados, o custo médio, qual o mercado consumidor, os planos para ampliar o nicho de consumo, relação com o público, tempo, a forma como os produtos são produzidos, embalados e entregues, além da matéria prima, questões de valores da marca e as dificuldades enfrentadas.

\subsubsection{Fase de Informação}

Seguindo a etapa metodológica, foi aplicada a entrevista para coleta de informações. Os produtos comercializados são calçados (sandálias) e carteiras. Com relação aos modelos, são disponibilizados 2 modelos de carteiras para venda e 14 de calçados. As informações pertinentes ao custo são ligadas ao fato de que não há gastos diretos referentes ao aluguel e energia, uma vez que a produção é feita na casa da proprietária e que o maior gasto é com os materiais do produto (como o solado, a linha para costura e cola), já outros são cedidos (câmara de ar e tecido para revestimento). Com relação aos preços dos produtos, eles variam entre $\mathrm{R} \$ 60,00$ e $\mathrm{R} \$ 120,00$.

A proprietária da empresa informou que o seu público consumidor está alinhado aos estudantes, principalmente os de design e arquitetura. Ademais, ela enfatiza o consumo pelos 
próprios colegas do design, que percebem o valor agregado ao conceito e processo do produto. Os clientes geralmente são as pessoas mais próximas a ela, a qual a mesma mantém contato, visto que, a própria marca carrega o seu nome, ou seja, está muito associada a persona Isabela Salles.

Além dessas pessoas, os calçados chamam atenção de um público mais alternativo, entre 19 a 28 anos. A faixa etária atual é a que apresenta satisfação com os produtos e a qual a empresária deseja continuar atendendo as necessidades, uma vez que ela tem mais facilidade em dialogar com do público jovem, devido ter uma linguagem pela qual ela está mais habituada, por essa razão, possui destreza de interagir com eles nas redes sociais.

Com relação ao conceito da marca, a proprietária responde que ao trabalhar a sustentabilidade, será chamada uma atenção maior a esse quesito, entretanto aqueles que consomem e procuram por seus produtos são os próprios colegas da graduação. Na verdade, o que mais chama atenção no produto é o próprio design. Na opinião da entrevistada, algumas pessoas que fazem parte do seu mercado consumidor adquirem seus produtos por uma questão de se mostrar diferente, de forma em que o produto torna-se algo relacionado à exclusividade, não encontrado com facilidade no mercado.

O processo produtivo da empresa é voltado ao trabalho artesanal, em que a designer domina os processos de produção do calçado e possui uma estagiária voluntária para Ihe auxiliar. Com relação à entrega dos produtos, a empresária não possui funcionário específico responsável pela entrega de calçados. Nesse sentido, percebe-se que a centralização do processo produtivo resulta em falta de tempo disponível para resolução de questões específicas da empresa, de forma que essa realidade é nociva à produtividade.

\subsubsection{Fase de análise}

Após o levantamento de dados sobre a empresa, realizada nas fases de preparação e informação, fez-se necessário organizar fatos para visualizar cada detalhe de maneira holística. Sendo assim, Pereira Filho (1994) propõe como próxima etapa a fase analítica que consiste no diagnóstico dos dados com uma visão mais criteriosa, de maneira a capturar os problemas que possam ser solucionados.

Nesta fase, ocorre à implementação da ferramenta de análise SWOT, que tem a finalidade de destacar os fatores interno (forças e fraquezas) e externos (oportunidades e ameaças) que implicam no sistema da empresa. De acordo com o autor, com a categorização dos dados (sendo denominado como funções) é possível capturar as funções críticas detectadas no processo produtivo, e logo, enunciar problemas a serem resolvidos.

Dentre as funções críticas, destaca-se que há períodos que a produção é pausada, por não haver demanda, e também, a designer ainda não produziu uma coleção de calçados, entretanto, é algo que desperta seu interesse futuramente. Ademais, o marketing digital, ação de comunicação para divulgação e venda dos produtos, é realizada somente por ela, bem como, nem sempre é atribuída à adequada atenção ao meio. Além disso, a empreendedora não possui o controle tão rígido dos gastos, desta maneira, em algumas situações, ocorre à mistura finanças pessoais com as da empresa.

Na subfase de enunciação dos problemas, destacaram-se os seguintes fatores: falta de estagiário, marketing digital não priorizado e centralização das responsabilidades. Segundo, Pereira Filho (1994), nesta subfase não ocorre apenas o relato do problema, mas também a elaboração de 
uma simples geração de ideias a fim de sanar as adversidades.

Neste momento, ocorre a aplicação de um breve brainstorming que gera as respectivas alternativas: efetivação de mais estagiários voluntários, sendo estes beneficiados por horas trabalhadas em currículo acadêmico; maior comprometimento com os meios de comunicação (marketing digital), tornando-se essencial a contratação de mais uma pessoa para exercer a função junto à proprietária. Como resultado ocorre uma divulgação mais eficaz, logo, aumenta o número de vendas; propor a divisão de tarefas com a entrada de novos estagiários, visto que, conforme Pestana (2003), o trabalho em equipe gera produtividade ao trabalho por meio da eficiência empregada nas atividades com a finalidade de atingir uma missão, projeto ou desafio com resultados eficazes.

\subsubsection{Fase criativa e desenvolvimento}

Durante a etapa criativa, foram geradas algumas ideias a partir dos problemas apresentados, e da análise da matriz SWOT, as quais deveriam ser propostas viáveis para que fossem aplicadas na empresa, como intuito de aumentar seu valor no mercado, além de potencializar a sua produção e venda. Um dos principais pontos é fazer com que a empresa tenha um contato mais próximo com seu público-alvo principal, os universitários. Logo, sugere-se a abertura de vagas de estágios voluntários, com o intuito de cobrir horas complementares para os discentes que estivessem precisando e tiverem interessem trabalhar com a empresa.

Outra forma de se aproximar com público e divulgar os produtos, seria se a empresa tivesse a oportunidade de ministrar palestras e oficinas com temas relacionados aos seus ideais nas universidades, durante eventos acadêmicos, por exemplo. Essa prática faz com que a empresa acabe gerando um buzzmarketing, o qual consiste em uma forma de divulgação voltada à peculiaridade do meio, o boca-a-boca que transcende a barreira do online fazendo com que as pessoas comentem sobre o assunto (LEITÃO; FÁVERO; PREDOLIM; FISCHER, 2009).

Além disso, na própria universidade, a empresa pode procurar parcerias com estudantes de áreas afins, como moda, design ou comunicação, para que sejam atendidas demandas internas, como a falta de mão-de-obra, auxílio para lidar com redes sociais e produção de material para divulgação. Dessa forma, serão aproveitados os conhecimentos do cliente para a elaboração de um produto e desenvolver um processo de integração, visto que o marketing cria mercados num processo que gera relacionamentos e vínculos, de forma que é benéfico a todos os elementos que interagem na troca (GOMES; KURY, 2013).

Por fim, seria interessante que a empresa estivesse presente em eventos que promovessem os mesmos ideais da empresa, como o Brazil Eco Fashion Week (BEFW), uma semana de moda sustentável que tem como objetivo atender um mercado de moda engajado com valores humanos e ecológicos. Outra maneira de divulgação, para o nicho que deseja ser alcançado, é através do portal ECOERA, uma plataforma online brasileira de compartilhamento de conteúdos, serviços e produtos sustentáveis.

As contribuições da metodologia AV/EV favorecem ao design uma capacidade mais estratégica, competitiva e econômica, e tudo isso está intimamente relacionado com o contexto atual. O design presta-se a atender complexidade do sistema, sendo que, a função do designer é solucionar os problemas do cotidiano com base em método projetual e como resultado gera produtos ou serviços a determinado grupo ou usuário (CARDOSO, 2013). A aplicação da 
metodologia AV/EV, em meio produtivo do design, colabora para o melhor desempenho de empreendimentos, auxilia na percepção e diminuição dos custos e que favorece o aumento da qualidade e torna o produto e/ou serviço mais competitivos perante mercado global.

\subsubsection{Fase de Implementação}

A fase de implantação é composta por quatro etapas: apresentação, planejamento, implantação e acompanhamento (PEREIRA FILHO, 1994). No caso da empresa de calçados pesquisada, as aplicações são limitadas a etapa de apresentação, em que os foram apresentados para a dona da empresa os estudos e propostas de intervenção para o empreendimento. Essa ação foi limitada, já que nenhum dos autores possui poder de decisão no negócio estudado.

\section{Conclusão}

O estudo da análise de valor direcionada à empresa de calçados "Isabela Sales Designer" foi produtivo, haja vista que o empreendimento possui grande capacidade crescimento por abordar não somente produtos, mas passarem conceitos que estão atrelados a identidade cultural de determinado público consumidor.

A partir dessa pesquisa, foi possível verificar que o valor é algo que tem como relação todo o processo e não apenas o preço, visto que o valor monetário de um produto é definido a partir do interesse e da forma que o produto é reconhecido no mercado. Além disso, foi possível verificar a viabilidade da aplicação de uma metodologia que usa como ferramenta a engenharia de valor na área do design, o que acaba agregando uma complexidade e qualidade ao produto.

A pesquisa apresentou como limitação a execução até a quinta etapa do Plano de Trabalho da metodologia AV/EV. A última fase não foi realizada, visto que a implantação das propostas sugeridas fica a critério da proprietária da empresa. Contudo, acredita-se que os resultados dessa pesquisa possam contribuir para a otimização da produção não só da empresa estudada, mas possam servir como modelo de inovação e sustentabilidade para outras organizações.

\section{Referências}

ANICET, A.; BESSA, P.; BROEGA, A. C. Ações na área da moda em busca de um design sustentável. In: Colóquio de Moda, 7., Parná, 11 a 14 set. 2011. Anais do VII Colóquio de Moda. Paraná: Cesumar, 2011.

CARDOSO, R. Design para um mundo complexo. São Paulo: Cosac Naify, 2013.

CASAGRANDE JR, E. F. Inovação tecnológica e sustentabilidade: possíveis ferramentas para uma necessária inferface. Revista Educação \& Tecnologia, n.ㅇ 8, set 2004.

CHIAVENATO, I.; SAPIRO, A. Planejamento estratégico: Fundamentos e aplicações. Rio de Janeiro: Elsevier Brasil, 2003.

DAYCHOUW, Merhi. 40 Ferramentas e Técnicas de Gerenciamento. Rio de Janeiro: Brasport, 2007.

FERRELL, O. C.; HERTLINE, Michael D. Estratégia de Marketing. São Paulo: Cengage Learning, 2009.

GALVÃO, N. de S. D.; MELO, R. de S. O método de análise SWOT como ferramenta para promover o diagnóstico turístico de um local: o caso do município de Itabaiana/PB. Caderno virtual de turismo, n.으 1, p. 118-130, abr 2008. 
GOMES, M.; KURY, G. A evolução do Marketing para o Marketing 3.0: O Marketing de causa. In: Congresso de Ciência da Comunicação na Região Nordeste, 15., Mossoró, 12 a 14 jun. 2013. Anais do XV Congresso de Ciência da Comunicação na Região Nordeste. Mossoró: Uern, 2013. p.1-11.

KOTLER, P. Marketing 3.0: As forças que estão definindo o novo marketing centrado no ser humado. Rio de Janeiro: Elsevier, 2010.

LAS CASAS, A. L. Marketing: Conceitos, Exercícios e Casos. São Paulo: Atlas, 2009.

LEITÃO, B. B.; FÁVERO, J. N.; PREDOLIM, L. da S.; FISCHER, L. Buzz Marketing: estratégias para atingir o consumidor na era digital e obter informações mercadológicas significativas. In: Congresso Nacional de História da Mídia, 7., Fortaleza, 19 a 21 ago. 2009. Anais do VII Congresso Nacional de História da Mídia. Fortaleza: Unifor, 2009. p.1-12.

MELO, D. J. de; BRITO, J. N.Utilização do método MTM-UAS como ferramenta de análise e aumento de produtividade. In: Congresso Nacional de Engenharia Mecânica e Industrial, 14., Bahia, 23 a 26 set. 2014. Anais do XIV Congresso Nacional de Engenharia Mecânica e Industrial. Bahia: Senai Cimatec, 2014.

OLIVEIRA, D. de P. R. Planejamento estratégico: conceitos, metodologia e práticas. São Paulo: Atlas, 2007.

PELTIER, F. Design sustentável: caminhos virtuosos. São Paulo: Editora Senac São Paulo, 2009.

PEREIRA FILHO, R. R. Análise do valor: Processo de melhoria contínua. São Paulo: Nobel, 1994.

PESTANA, Maria Cláudia et al. Desafios da sociedade do conhecimento e gestão de pessoas em sistemas de informação. Ciência da Informação, v. 32, n. 2, 2003. 